Finally, is there in glaucoma some dark sinister factor which pathology has so far failed to grasp, some nameless, hitherto shadowy, influence for evil, whose detection has evaded all the means at our disposal ?

These are very difficult questions, but not less attractive and important on that account. Nothing will do more to hinder the advance of our knowledge of glaucoma than the assumption that we really understand the subject, and probably nothing will be more likely to lead to progress than a candid exposure of the depth of our ignorance. For these reasons the writer does not hesitate to ask such questions as the above without making any serious attempt for the present to provide an answer to them.

\title{
SLOUGHING CORNEA IN GRAVES'S DISEASE AND IN DISSEMINATED SCLEROSIS
}

BY

\section{T. HARRISON BUtLER}

LEAMINGTON SPA.

ARNOLD KNAPP contributed to the Archives of Ophthalmology for March, 1918, a paper upon the loss of the cornea in Graves's disease. This catastrophe is not, he says, so very uncommon, and he recounts a case in which he succeeded in saving useful vision in one eye. In the following case first one cornea and then the other sloughed away, and ultimately the patient died.

On February 7, 1918, Mrs. P., aged 40, was sent to consult me by Dr. Bury, of Leamington Spa, who had tried every known treatment to relieve the symptoms of an aggravated case of exophthalmic goitre. On examination, in addition to all the usual signs of the disease, I found that there was an exaggerated proptosis of each globe, so much indeed that, when the eyes were closed as much as possible the left cornea was exposed. I strongly advised Mrs. P. to let me suture the left lids together. She was unwilling to follow this advice, and I did not see her again till March 2, 1918, when I examined her in bed at her own home. I found intense chemosis and brawny swelling of the conjunctiva of both eyes: the proptosis was even more pronounced : and the left cornea was infiltrated in its lower quadrant, and was anaesthetic. The tension of both eyes appeared to be raised, but there was nothing in their appearance to suggest glaucoma. I concluded that the apparent hardness was due to the tense state of the tissues behind the eye. Subsequent examination with the Schiötz tonometer showed that the tension was 20. I admitted Mrs. P. to the Warneford Hospital, where we instilled atropin, and carefully bandaged the eye. On March 3 a definite ulcer had formed in the 
lower portion of the left cornea. In spite of treatment the ulcer slowly spread, and onyx appeared. On March 7 I freely incised the swollen conjunctiva and performed a Guthrie's section upon the cornea. Pus escaped from the layers of the cornea. Incisions into the brawny conjunctiva did not diminish the swelling, and blood alone escaped from the cut surfaces. This treatment proved futile. On March 9 under ether I freely cauterized the ulcer and sutured the lids together. As recommended by Priestley Smith, each lid was split from canthus to canthus, the raw surfaces everted and sewn together. On March 11 the sutures all cut out and the eye reopened. On March 27 the ulcer which was still spreading was again cauterized and covered with a conjunctival flap. This flap failed to remain over the cornea. The cornea finally sloughed and the eye, which was intensely painful, was enucleated under ether.

On March 24, the right cornea which had never been anaesthetic, began to ulcerate. In spite of treatment the cornea soon sloughed away. The general condition of the patient was so bad that no active measures were adopted to save the second eye, and after another fortnight she died of heart failure.

It is noteworthy that after removal of the eye the conjunctiva remained brawny and turgid.

The disease was so severe that I doubt whether earlier treatment would have saved the eyes, nor indeed did there seem much chance that her life would be preserved. In spite of the rapid and feeble pulse, ether anaesthesia by the open method was well tolerated, and the two operations were not followed by any shock or aggravation of symptoms.

In January, 1919, I was consulted by Mrs. M., age 36. The history was that she was quite well two years ago when she noted that the left leg began to drag after a long walk. She was found to be suffering from disseminated sclerosis. Examination showed that her knee jerks were greatly exaggerated, that she had well developed ankle clonus, and that she had great difficulty in walking. The right eye began to water in September, 1918, and the lid drooped. In October the eye became inflamed. When I examined her the right eye was injected, the cornea was anaesthetic and was perforated in its lower aspect. The anterior chamber was threequarters full of pus. The upper half of the cornea had a healthy appearance. Mrs. M. was admitted to the Coventry Hospital. In spite of treatment the cornea sloughed away. The left eye remained normal. The end of the case was tragic in its suddenness. One day Mrs. M. was peacefully eating her dinner sitting up in bed, when without warning she became cyanosed and convulsed. She died before it was fully realized that she was in any danger. A post-mortem examination showed no cause for her asphyxia, which 
was apparently due to laryngeal spasm. I am informed that it is not unusual for patients with disseminated sclerosis to die in this manner. The loss of the eye was undoubtedly due to trophic changes probably caused by a sclerotic area in the nucleus of the fifth nerve. I am not aware that such a case has been described before, and it must be very unusual.

\section{COUNCIL OF BRITISH OPHTHALMOLOGISTS}

\section{Report on the Standardization of the Notation of the Axes of Cylinders}

The Council is of the opinion that the absence of any agreed standard for the notation of the axes of cylinders is liable to give rise to mistakes in the making up of spectacle prescriptions. It finds that it is the practice of most opticians in this country to transcribe all prescriptions into a definite standard notation before sending them into the workshop. The Council considers that it is undesirable that the necessity for this should exist, for it is beyond doubt that when these prescriptions fall into the hands of less careful opticians, many mistakes arise, which would be avoided if ophthalmic surgeons adopted a standard notation.
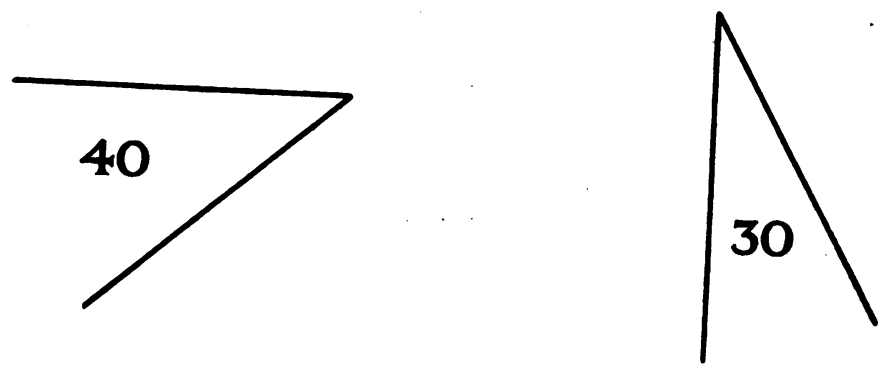

FIG. 1.

The methods of notation in use may be grouped as follows:

(A) That in which angles only up to $45^{\circ}$ are used.

In this method, a diagram is drawn indicating the axis and the nearest horizontal or vertical meridian. The value of the angle separating the lines is written between them.

(B) Those in which angles up to $90^{\circ}$ are used:-

(1) The horizontal meridian is taken as zero, and the angle is always read below. Thus " $60^{\circ}$ Down and In" means that the axis is separated from the horizontal by $60^{\circ}$ and is pointing 